\title{
Effects of Ethanolic CowpeaExtract on MDA,SOD, TNF- $\square$ Levelsand Neuron Cell Vacuolationin WistarRat Brain After Exposed with Gasoline Fume
}

\author{
Zamroni Afif ${ }^{1}$, Dessika Rahmawati ${ }^{1}$, M. Dalhar ${ }^{2}$, M. Aris Widodo ${ }^{3}$ \\ ${ }^{1}$ Student of Postgraduate Program, Department of Biomedic, Brawijaya University, Malang, Indonesia \\ ${ }^{2}$ Specialist Consultant, Department of Neurology, Saiful Anwar General Hospital, Faculty of Medicine, \\ Brawijaya University, Malang, Indonesia \\ ${ }^{3}$ Professor,Department of Pharmacology, Faculty of Medicine, Brawijaya University, Malang, Indonesia
}

\begin{abstract}
This study evaluates the effect of ethanolic cowpea extract (CE)on inhibitingthe decrease of SOD and the increase of MDA, TNF- $\alpha$ level and neuron cell vacuolationinrat brainafter exposed with the gasoline fume. This study were divided into 8 groups: 1)Negative control with no fume exposure and CE(-), 2)No fume exposure with $C E(+), 3)$ Fume exposure for 2 minutes with $C E(-), 4) F u m e$ exposure for 2 minutes with $C E(+)$, 5)Fume exposure for 3 minutes with CE(-), 6)Fume exposure for 3 minutes with CE(+), 7)Fume exposure for 4 minutes with $C E(-)$, 8) Fume exposure for 4 minutes and $C E(+)$. All groups received oxygen for 4 minutes. There was a significant difference between groups which were treated with cowpea supplementation and groups without the treatment in terms of SOD activities $(p<0,05)$ in 4 minutes exposure groups, MDA and TNF- $\alpha$ levels $(p<0,05)$ in all exposure groups. In addition, there was an insignificant difference $(p>0,05)$ on vacuolation in all exposure groups. In conclusion, ethanolic extract of cowpeas inhibits the decrease of SOD and the increase MDA and TNF- $\alpha$, but does not reduce cell vacuolation in rat brain tissues after exposed to gasoline fume.
\end{abstract}

Key word: Vigna unguiculata, SOD, MDA, TNF- $\alpha$, vacuolation, gasoline fume.

\section{Introduction}

Air pollution is the most common environmental factor that induces inflammation and oxidative stress in central nervous system (CNS). Apart from its relation with increasing risk of lung and cardiovascular diseases, air pollution also relates with CNS diseases like Parkinson and stroke. ${ }^{1}$

Particles from vehicles can reach brain circulation. ${ }^{2}$ Expose of fumes from gasoline to astroglia, microglia, neuron and blood brain barrier can increase proinflamatory cytokines and oxidative stress which leads to cell apoptosis. Tumor Necrosis Factor (TNF- $\alpha$ ) is an important mediator of inflammation which plays role in many neurologic pathogenesis. ${ }^{3}$

The source of cellular oxidative stress is still unclear. It may include mitochondrial dysfunction, increase of dopamine metabolism, hydrogen peroxide, and other reactive oxygen species (ROS), increase of ferrous reactivation, and destruction of oxidative defense pathway. ${ }^{4,5}$

Antioxidants can prevent inflammation as scavengers for free radicals and prevent oxidative stress. Therefore, antioxidants and antiinflammation substances that can prevent inflammation process in the brain arevital. $^{6}$

Cowpeas (Vignaunguiculata) contain many types of flavonoid fitoestrogen including genistein, quercetin, kaempherol, and daidzein. Antioxidant and antiinflammation effect of cowpea may prevent oxidative stress and neuroinflammation to avoid cell damage. ${ }^{7}$

The aim of this study is to know the effect of cowpea extract on the level of superoxide dismutase (SOD), malondialdehyde (MDA), TNF- $\alpha$ and morphology of damaged cell (vacuolation) of the rat brain after being exposed togasoline fume.

\subsection{Location of Study}

\section{Material And Method}

The present study was conducted at the Department of Pharmacology and Biomedic, Faculty of Medicine, Brawijaya University, Malang, Indonesia.

\subsection{Study Design}

Object of this experiment are rats which are divided into 8 groups based on treatment applied to each group. The eight groups were: 1)Negative control with no fume exposure and no cowpea extract (CE), 2)No fume exposure with CE supplementation(+), 3)Fume exposure for 2 minutes with CE supplementation(-), 
4)Fume exposure for 2 minutes with $\mathrm{CE}$ supplementation(+), 5)Fume exposure for 3 minutes with $\mathrm{CE}$ supplementation(-), 6)Fume exposure for 3 minutes with CE supplementation(+), 7)Fume exposure for 4 minutes with CE supplementation(-), 8) Fume exposure for 4 minutes and CE supplementation(+). All groups received oxygen for 4 minutes.

\subsection{Fume Exposure Instrument}

Instrument to expose rats with fume consists of glassboxes for exposure place, oxygen storage tube, grass cutting machine to create fume, fume reservoir to stabilize temperature and pressure of fume from the machine. In the tool, there was also a pipe that distributes $\mathrm{O}_{2}$ and fumes which is equipped with valve. This instrument was modified by Pharmacology Laboratory, Faculty of Medicine,Brawijaya University, Malang, Indonesia.

\subsection{Cowpea Extraction}

The first step to get cowpeas extraction was drying cowpea by using oven at $40-60{ }^{\circ} \mathrm{C}$. Afterwards, the dried cowpeas were crushed and macerated with ethanol and left overnight to settle. The maceration process was repeated for 3 times. The result was then evaporated. Extraction results were poured into bottles made of glass.

\subsection{Exposure of Gasoline Fume}

Rats were weighed, and placed for exposure with the tools set. Treatment groups (group 2, 4, 6, and 8) were feed with cowpea extract for 30 minutes before being exposed. Each group contains of 4 rats caged inside a closed box. The engine was started and the faucet forfume and $\mathrm{O}_{2}$ distribution were opened in accordance with the specified time. Exposure were carried out for 30 days.

\subsection{Rat Brain Extraction}

Rats were anaesthetized with ether and brains were collected from cranium and divided into two coronal sections. Brain specimens were stored in $-80^{\circ} \mathrm{C}$ until the analysis time was started.

\subsection{Measurement of SOD Activity}

Brains were sliced into $200 \mathrm{mg}$ and homogenized with $2 \mathrm{cc}$ phosphate buffer at $\mathrm{pH}$ 7.4. The specimens were centrifuged at $4^{\circ}$ with speed of $4000 \mathrm{rpm}$ for 15 minutes. Next, $200 \mu \mathrm{L}$ EDTA, $100 \mu \mathrm{L}$ NBT $25 \mathrm{U}, 100 \mu \mathrm{L}$ xanthine $25 \mathrm{U}, 100 \mu \mathrm{L}$ XO $1 \mathrm{U}$ were added to the specimens. Afterwards, the brain specimens were incubated at $39^{\circ} \mathrm{C}$ for 30 minutes, centrifuged at $3000 \mathrm{rpm}$ for 15 minutes, and blended with $3 \mathrm{cc}$ aquabidest. Finally, the solution was read with a spectrophotometer on $\lambda 580 \mathrm{~nm}$.

\subsection{Measurement of MDA Levels}

$150 \mathrm{mg}$ brain samples were homogenized by adding $2 \mathrm{cc}$ phosphate buffer. $250 \mu \mathrm{L}$ of $40 \%$ TCA, $200 \mathrm{cc}$ $\mathrm{HCl}$ and $250 \mu \mathrm{L}$ TBA (thio $\mathrm{Na}$ ) consecutively. $200 \mu$ Lsolution was added with $0.5 \mathrm{cc}$ aquabidest and heated for 25 minutes. Centrifuge was performed at $3000 \mathrm{rpm}$. The supernatant was taken and added with $3 \mathrm{cc} \mathrm{H}_{2} \mathrm{O}$ and was read with a spectrophotometer on $\lambda 532 \mathrm{~nm}$.

\subsection{Measurement of TNF- $\square$ Levels}

0.5 grams of frozen brain tissues were thawed and homogenized by mashing up and adding of lysis buffer (PBS, Tris base, EDTA, NaCL, PMSF, NP 40) and protease inhibitor.Homogenates were centrifuged at $12000 \mathrm{rpm}$ for $10 \mathrm{~min}$, homogenates were separated from the supernatant. The levels of TNF- $\alpha$ determined using ELISA kits from R\&D Systems.

\subsection{Histopathologic Preparations and Observation of Brain Tissue}

Brain tissues were soaked with formalin, sliced into 2-3 mm thick, and processed using Tex Tissue Processor machine. Tissues which were lifted from the Tex Tissue Processor machine were blocked with paraffin in accordance with tissue code. The blocks were cut with microtome for 3-5 microns thickness. After sliced, it was put in the oven for 30 minutes at a temperature of $50-70^{\circ} \mathrm{C}$, then put into two tubes of xylol solution for 20 minutes each, afterward it were rinsed by alcohol for 3 minutes, and water for 15 minutes. The slides were stained by hematoxillin-eosin. They were observed under the microscope at a magnification 400x to see cells with vacuolation.

\subsection{Data Analysis}

Data were analyzed with ANOVA test followed by correlation test using SPSS 15.0. 


\section{Results}

3.1 Effect of Ethanolic Cowpea Extract (Vignaunguiculata) onLevelof Superoxide Dismutase (SOD)

ANOVA analysis showed that there is a significant difference of SOD activities $(p<0,05)$ in 4 minutes exposure between groups with and without cowpea supplementation (Figure 1).

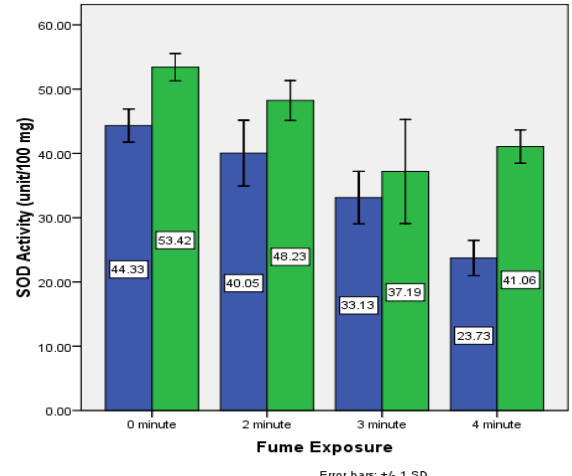

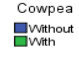

Figure 1.Effect of Ethanolic Cowpea Extract (Vignaunguiculata) on SOD Activitiesof Rat Brain Tissue

3.2 Effect of Ethanolic Cowpea Extract (Vignaunguiculata) on MDA Level.

ANOVA analysis showed that there is a significant difference of MDA levels $(p<0,05)$ in all groups exposure between group with and without cowpea supplementation (Figure 2).

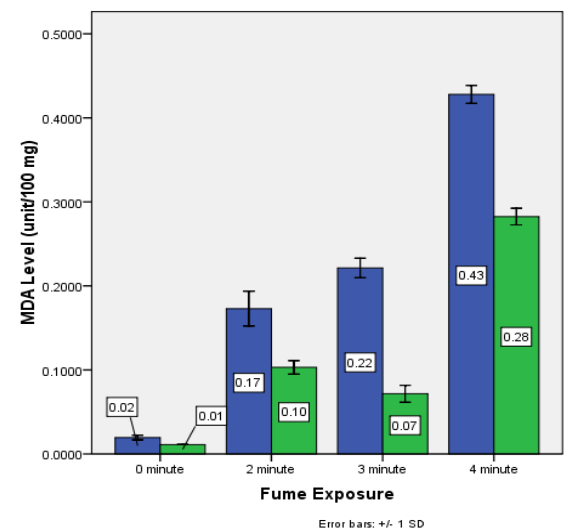

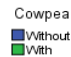

Figure 2.Effect of Ethanolic Cowpea Extract (Vignaunguiculata) on MDA Levels of Rat Brain Tissue

3.3 Effect of Ethanolic Cowpea Extract (Vignaunguiculata) onTNF- $\square$ level.

The ANOVA analysis showed that there is a significant difference of TNF- $\alpha$ Levels $p<0,05$ )in all groups exposure between group with and without cowpea supplementation (Figure 3).

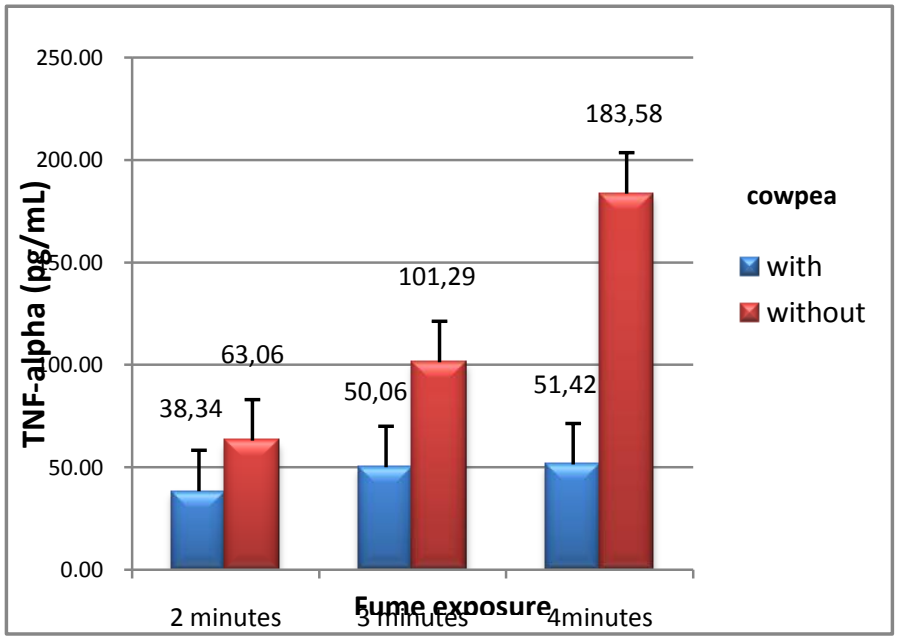

Figure 3.Effect of Ethanolic Cowpea Extract (Vignaunguiculata) of TNF- $\square$ Levels an Rat Brain Tissue 
3.4 Effect of Ethanolic Cowpea Extract (Vignaunguiculata) of neuron cell damage (Vacuolation) of the Rat Brain

ANOVA analysis showed thatthe difference of vacuolation between group with and without cowpea supplementation is insignificant $(p>0,05)$ (Figure 4).

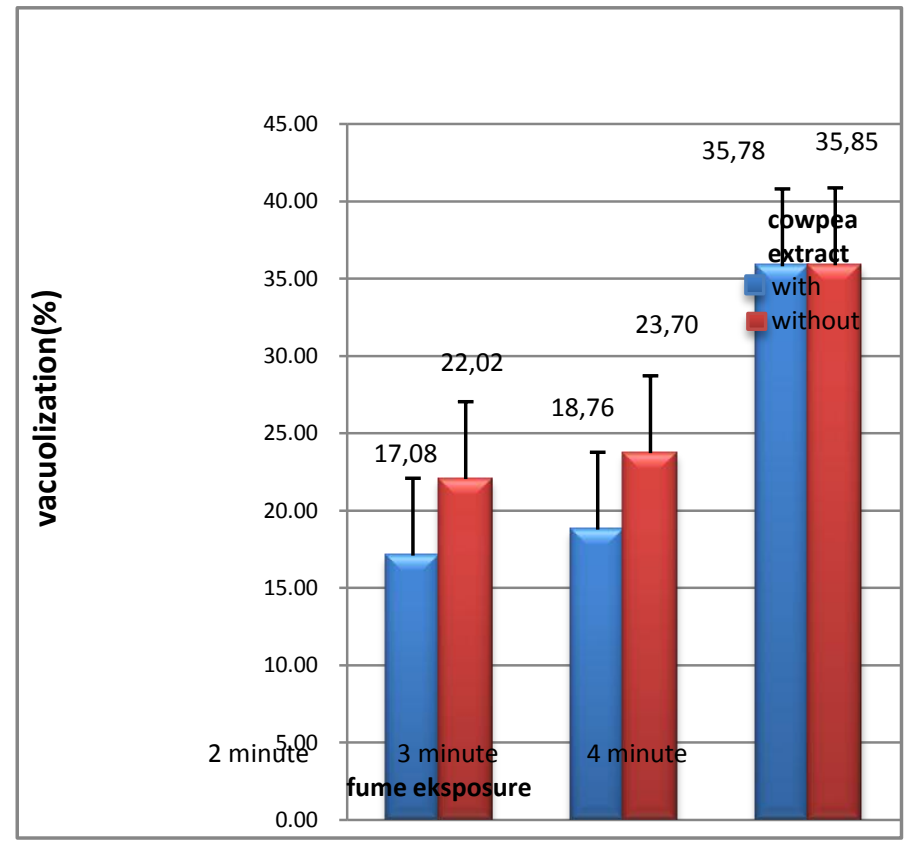

Figure 4.Effect of Ethanolic Cowpea Extract (Vignaunguiculata) of Cell Morphology (Vacuolation) of the Rat Brain Tissues
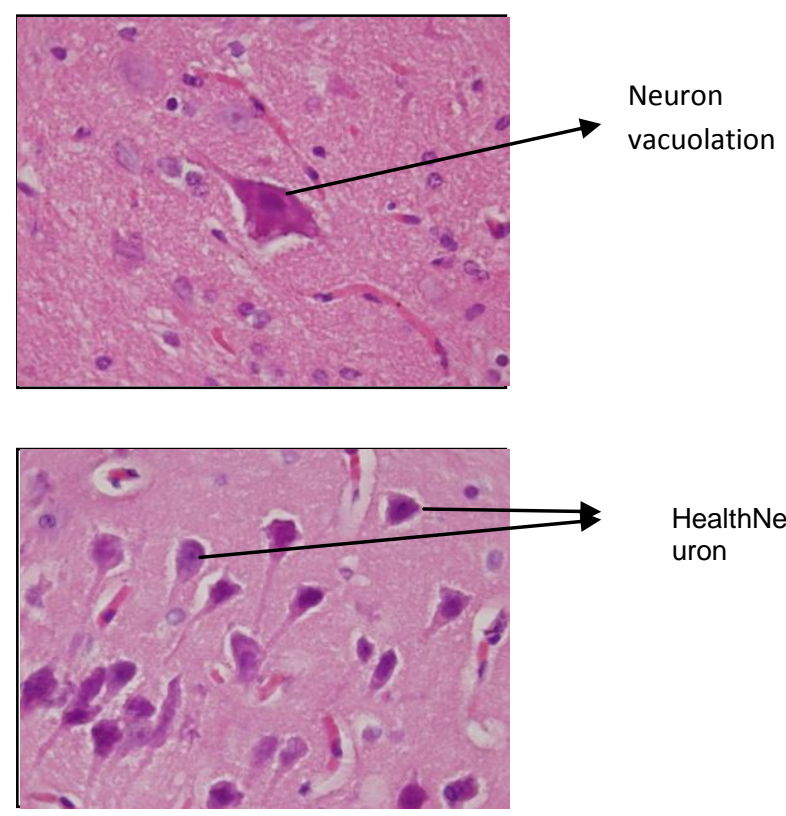

Figure 5. Showing normal and neuronal damage (vacuolation) (magnificient 1000x)

3.5 Correlation between SOD Activity, MDA, and TNF- $\square$ Levels and Cell Morphology (vacuolation) of The RatsBrain

There was a significant correlation of SOD activity with MDA level $(r=-0,747$ with $p=0,000)$ and TNF$\alpha$ level $(r=-0,702$ with $p=0,000)$ in rats brain to engine fume exposure for 2 nd,3rd and 4 th minute. It showed that the higher level of brain MDA and TNF- $\alpha$ thelower was the brain SOD. 
There is a significant correlation of MDA level with TNF-alevel $(r=0,724$ with $p=0,000)$ and vacuolation $(r=0,627$ with $p=0,000)$ in rat brains to engine fume exposure for the $2 \mathrm{nd}, 3$ rdand 4 th minute. It showed that the higher level of brain MDA, the brain TNF-alevel and neuron cell damage was higher.

Correlation test showed a significant correlation between TNF- $\alpha$ concentration with brain cell vacuolation amount $(r=0,727$ with $p=0,001)$. This inflammation state with increasing TNF- $\alpha$ can cause neuron cell damage.

\section{Discussion}

SOD acts to change very unstable superoxide anion $\left(\mathrm{O}_{2}\right)$ into slightly reactive hydrogen peroxide radical $\left(\mathrm{H}_{2} \mathrm{O}_{2}\right)$ and oxygen $\left(\mathrm{O}_{2}\right) .{ }^{8}$ This study shows that a longer fume exposure gives higher levels of free radicals. Hence, the activity of brain SOD was decreased.

Increased levels of MDA was equal with the duration of fume exposure which would increase production of ROS (Reactive Oxygen Species), ROS would degrade polyunsaturated fatty acid to malondialdehyde (MDA). The longer fume exposure, the more fatty acid was degraded which in turns productedmore MDA.

Study regarding the effect of cowpea extract on SOD levels had been done before. The result of this study was similar with study written by Huang and Zhang (2010) that showed genistein supplementation (2,5 $\mathrm{mg} / \mathrm{kgBW}$ ) the daily injected subcutaneous for 30 days increased SOD serum levels and decreased MDA levels in rats.Genisteinhastherapeuticpotentialto reducecognitivedisordersandneurodegenerativediseases.Genistein hadan antioxidant properties through estrogenicpathway. ${ }^{9}$

Analysis of rat brain tissues shows that the SOD activity levels were significantly higher while MDA levels were lower after supplementation using cowpeas extract.

The results ofthisstudyare consistentwiththe research hypothesis, thatcowpeaextract which containsflavonoidcompoundssuch asflavonolsgroup(quercetin, kaempferol, andmyricetin) andderivedisoflavones(genisteinanddaidzein) may inhibit thedecrease SOD activityandincrease MDAlevels in brain of rats afterexposed togasolinefumethroughthe inhibition offree radical reactions.

TNF- $\alpha$ indicates theamount ofinflammationthat occurs inthe braintissueof ratgroups which were treated with fume.TNF- $\alpha$ is amajorinflammatory mediatorproducedbymicroglia, bothin theacute phase responseas well asduring thechronicphasewhich plays an important roleinvariousneurologicaldisorders. ${ }^{3}$

This studyshowsthat thegroup ofrats receivingcowpea extractsupplementation for 30minutesbeforefume exposurehave lower levels ofTNF- $\alpha$ in comparison with thegroupsof ratswithout cowpea extract supplementation. This result is significant in all exposure times of 2nd, 3rdor4thminutes. Thuscowpeasextractcanprevent theincrease ofTNF- $\alpha$ inratbrain which has been exposed tofume.

The activated neuron cellsproduceproinflammatorymediatorssuch ascytokine, chemokine, macrophageinflammatoryprotein, monocytechemoatractantproteins, prostaglandins, leukotrienes, thromboxane, coagulation factors, ROS, NO, complement, proteasesandC-Reactive Protein. Activatedglial cellsalso produceReactiveOxygenSpecies(ROS). If there is prolongedROSproduction, the storage ofantioxidants isdepletedand this may increase celldamage. ${ }^{10}$

Fume exposurecauses an increaseofproinflammatorycytokinesandoxidativestresswhich is the beginningofcell death(apoptosis). TNF- $\alpha$ is reportedto have2receptorsignalingpathways, namelyP55andP75. Both receptorswere detectedinthe central nervoussystem. The functionofp75receptoris still unclear butactivationofP55receptorsinitiateapoptosis. $^{3}$

Flavonoidincowpeasuch asgenistein, daidzein, kaempferol, andquercetin serves asan anti-inflammatory agent as well asantioxidant. In addition toantioxidantproperties, genisteinalso has anantiinflammatoryeffectsbyinhibitingthe production ofproinflammatorymoleculesinhumanchondrocytes. ${ }^{11}$ Quercetinhasanti-inflammatoryeffectsbyinhibitingthe production ofNOandinhibition ofthe enzymecyclooxygenase-2 (COX-2). ${ }^{7}$

The result showedthat therewas no difference inthe effect ofcowpeaextractsagainst cell damage(vacuolation) betweenthe group withoutcowpeaextract supplementation and those with supplementation onfume exposure for 2nd,3rdand4thminutes. Thus, thecowpeaextracthave no effecttoprevent brain cell damage. This islikely due to the process of cell death(apoptosis) is notonly caused byinflammatory factors, butis also influenced by otherfactorssuch asfree radicals.

Study conducted by Nwaoparaet al (2009) found that the histological changes in the brain of rats that were exposed to Yaji (MSG) showed marked neurodegenerative patterns including neuronal cell death, gliosis, inflammation, axon or myelin sheath damage. ${ }^{12}$ In addition, according to research conducted by Varner et al (1998), there was an increase in protein staining, picnosis, vacuolation, presence of ghost - like cells decrease in the density of neurons in rats that were given fluoride on its drink. ${ }^{13}$

Neurons morphology in response tothe presence ofcellinjuryisautolysis, where theneurons areshrunkenand turns basophilic. Cell nucleusalsoshrinks. Simultaneously,the glial cellsaroundneuronsandblood vesselsabsorb waterresulting in formation ofthe vacuole. 
Morphology of cell damage is also affected by the animals age when their brain tissues were collected. Possibility of bias may also be contributed by damage occurred during tissue collection and storage, and limitation of observation with simple staining methods.

\section{Conclusion}

This study conclude that ethanolic extract of cowpea (Vignaunguiculata) inhibit the decrease of SOD, increase of MDA and TNF- $\alpha$; however, it does not reduce cell vacuolation in rat brain tissue after being exposed to gasoline fume.

\section{Acknowledgment}

This research was funded by Ministry of Education and Culture, Indonesia.The study was cleared by The University Ethics Committee, Brawijaya University, Malang, Indonesia.Ethical clearance No. 127 KEPKFKUB/05/2012.

\section{References}

[1] Block, M.L., and Calderon-Garciduenas L., Air Pollution : Mechanisms of Neuroinflammation\& CNS Disease. Trends Neurosci. 2009.32(9): 506-516.

[2] Elder, A., Gelein, R., Silva, V., et al.. Translocation Of Inhale Dultra Fine Manganese Oxide Particles To The Central Nervous System. Environmental Health Perspectives, 2006.114: 1172-78.

[3] Lucas S M, Rothwell N J, Gibson R M, The Role of Inflammation in CNS Injury and Disease, British Journal of Pharmacology.2006.vol 147; 232-240

[4] Moore, et al.,Molecular Pathophysiology of Parkinson's Disease. Annu. Rev. Neurosci.2005.28: 57-87.

[5] Balamurugan, G., and Muralidharan P., Effect of Indigoferatinctoria on $\beta$-amyloid (25-35) Mediated Alzheimer's disease in Mice : Relationship to Antioxidant Activity, Bangladesh J Pharmacol. 2010.5: 51-56.

[6] Broughton BRS, Reutens DC, SobeyCG.,Apoptotic Mechanisms After Cerebral Ichemia. Stroke AHA.2009;e331-7

[7] Hamalainen, Mari, Nieminen R., Vuorela P., Heinonen M., Moilanen E., Anti-Inflammatory Effects of Flavonoids: Genistein, Kaempferol, Quercetin, and Daidzein Inhibit STAT-1 and NF-Kb Activations, whereas Flavone, Isorhamnetin, Naringenin, and Pelargonidin Inhibit Only NF-Kb Activation Along with Their Inhibitory Effect on INOS Expression and NO Production in Activated Macrophages. Mediators Of Inflammation. 2007. Hindawi Publishing Corporation.

[8] Ziccarelli, V. E., An In Vivo Study of The Antioxidant Potentials of Plant Food Concentrates. A thesis submitted to the Faculty of Graduate Studies and Research in partial fulfillment of the requirements for the degree of Master of Science in Nutritionand Metabolism Department of Agricultural. Food and Nutritional Science. 2001. University of Alberta.

[9] Huang, Y., and Zhang Q. Genistein Reduced the Neural Apoptosis in the Brain of Ovariectomised Rats by Modulating Mitochondrial Oxidative Stress. British Journal of Nutrition. 2010. 104: 1297-130.

[10] Rubio-Perez J.M, Morillas-Ruiz J.M., A Review: Inflammatory Process in Alzheimer's Disease, Role of Cytokines, The ScientificWorld Journal. 2011.

[11] Hooshmandet al., GenisteinReduced the production of Proinflammatory Molecules in Human Chondrocytes, $J$ Nutritional Biochemistry.2007.p:609-614.

[12] Nwaopara, A.O, Histological Signs of Neurodegeneration in the Cerebrum of Rats Fed with Diet Containing Yaji: The Complex Nigerian Suya Meat Sauce, Asian Journal of Medical Sciences.2009.2(1): 16-21.

[13] Varner, J.A., Jensen, W., Horwath and R.L. Issacson, Chronic Administration of Aluminium or Sodium Fluoride to Rats in Drinking Alterations in Neuronal and Cerebrovascular Integrity. Brain Res., 1998.784:284-298. 